\title{
Global Factors in Budget Deficits
}

\author{
Christopher J. Neely
}

$\mathrm{D}$ iscussions about fiscal deficits - government outlays less tax receipts as a percentage of gross domestic product (GDP) - often overlook the importance of global factors in common movements across countries. The left panel of the figure, for example, shows that deficits in Canada, France, Germany, the United Kingdom, and the United States declined from the mid- to the late-1980s, increased with the global recession of 1990, and then improved again from about 1992 through 2000. Recently, however, deficits have increased; in Germany and France, they are larger than the European Monetary Union limit of 3 percent of GDP.

Why do national fiscal deficits tend to move together? One reason is that deficits react to common business cycle shocks. That is, global economic activity is subject to common shocks to technology, demographics, commodity prices, and political uncertainty. Further, international trade links countries' economies. Over a business cycle, government outlays fall and tax receipts rise with economic activity. Such changes are called automatic stabilizers; they make deficits vary with the business cycle. Governments often raise discretionary spending or cut taxes during periods of low output, further amplifying the connection of deficits to economic activity. Because countries tend to share business cycles, which are correlated with deficits, deficits tend to be correlated internationally.

The portion of a deficit that is due to the level of economic activity is called the cyclical deficit, while the structural deficit is the shortfall that would exist even if the level of economic output were at its potential. The right panel of the figure shows estimates of structural deficits.

Structural deficits can result from changes in tax and spending preferences or external events. For example, the U.S. deficit rose in 1992 when savings and loan depositors were bailed out. And the terrorist attacks of September 11, 2001, and wars in Afghanistan and Iraq surely inflated the U.S. deficit through higher defense and homeland secu- rity expenditures. Indeed, the U.S. deficit in 2002 (3.4 percent of GDP) was mostly structural (2.9 percent), not cyclical.

The international correlation in structural deficits illustrates that the business cycle is not the only global influence on fiscal deficits. For example, the "peace dividend," the cuts in defense spending after the fall of the Soviet Union, accounted for some of the international fall in structural deficits in the 1990s. Similarly, the extraordinary international bull market in equities in the late 1990s - which was only weakly related to real economic activityprobably reduced deficits by increasing tax revenues on capital gains. The decline in equity prices since 2000 has been associated with a falloff in tax revenues on capital gains. Finally, the Maastricht Treaty, which established the European Monetary Union on January 1, 1999, limits deficits to 3 percent of GDP. This treaty obligation forced cuts in French and German deficits in the 1990s.

In evaluating deficits, one should carefully consider the source. Cyclical deficits, which often have a strong global component, do not threaten long-term fiscal solvency because they will be reversed over time. However, large structural deficits-those greater than the country's average output growth rate-cannot be maintained forever and might require adjustments to tax and spending policies.

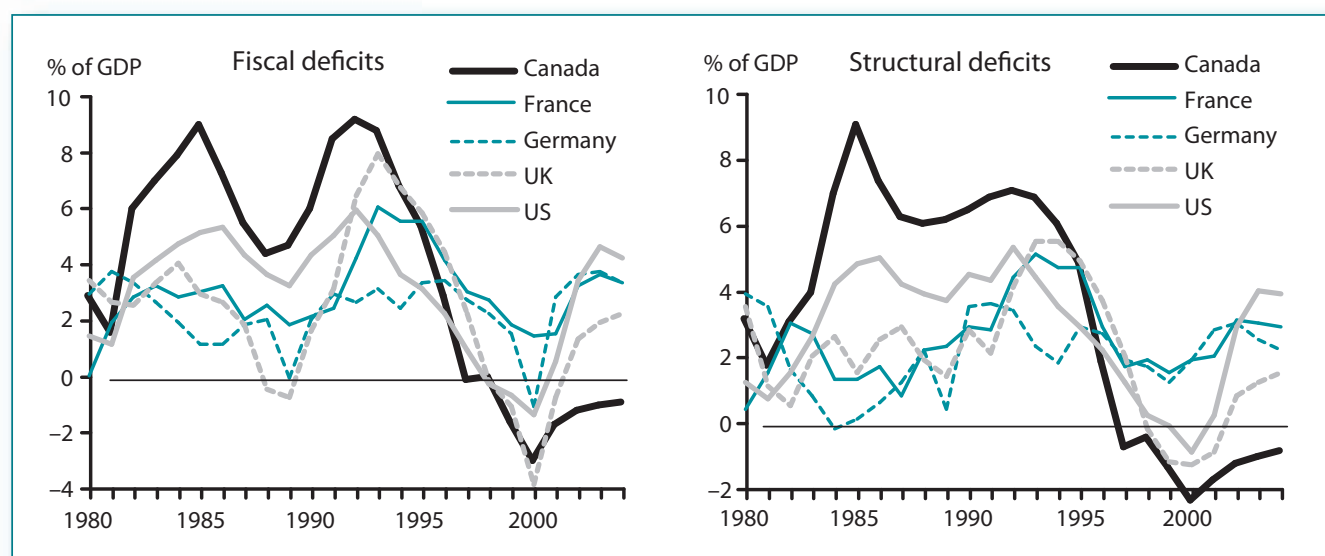

SOURCE: OECD Economic Outlook.

NOTE: The panels show fiscal deficits and structural deficits as a percentage of GDP. Deficits are measured as a percentage of GDP because larger, richer economies can more easily afford to run higher deficits than can poorer countries. Figures for 2003 and 2004 are projections. 